\title{
OCCUPATIONAL BURNOUT AND ITS OVERLAPPING EFFECT WITH DEPRESSION AND ANXIETY
}

\author{
KRYSTYNA GOLONKA ${ }^{1}$, JUSTYNA MOJSA-KAJA ${ }^{1}$, MATEUSZ BLUKACZ ${ }^{2}$, MAGDA GAWŁOWSKA ${ }^{1}$, \\ and TADEUSZ MAREK ${ }^{1}$ \\ Jagiellonian University, Kraków, Poland \\ ${ }^{1}$ Institute of Applied Psychology, Faculty of Management and Social Communication \\ ${ }^{2}$ Institute of Psychology, Faculty of Philosophy
}

\begin{abstract}
Objectives: The problem of defining burnout concerns its overlapping effect with other syndromes and disorders, such as depression and anxiety. Additionally, some individual characteristics influence susceptibility to burnout (e.g., neuroticism). Therefore, the question arises whether burnout is or is not a distinct syndrome. The aim of the study is to compare 2 distinct burnout measures by analyzing their connections with organizational and individual variables. Material and Methods: The study was conducted in the Institute of Applied Psychology at the Jagiellonian University, Kraków, Poland on a group of employees ( $\mathrm{N}=100 ; 40$ men; mean age 36.03 years). All participants completed 2 burnout scales: the Maslach Burnout Inventory - General Survey (MBI-GS) and the Link Burnout Questionnaire (LBQ). Organizational and individual factors were controlled with Areas of Worklife Survey, State-Trait Anxiety Inventory, NEO Five-Factor Inventory and Beck's Depression Inventory scales. A structural equation path model was created to quantify the relations between organizational factors and burnout, as well as to control the individual factors of anxiety, neuroticism and depression. Results: The results indicate high compatibility between MBI-GS and LBQ on burnout diagnosis. The MBI-GS and LBQ revealed stronger connections with organizational context and individual characteristics, respectively. Depression explains dimensions of exhaustion (MBI-GS, LBQ), sense of disillusion (LBQ), neuroticism-exhaustion (MBI-GS); anxiety explains sense of professional inefficacy (LBQ). Conclusions: Besides organizational variables, individual characteristics also play an important role in explaining burnout syndrome. Exploring the 2 burnout models has revealed that depression is an important determinant of exhaustion. Cynicism and relationship deterioration have consistently been explained only by organizational context. Int J Occup Med Environ Health. 2019;32(2):229-44
\end{abstract}

Key words:

depression, anxiety, burnout, neuroticism, MBI-GS, LBQ

\section{INTRODUCTION}

Burnout is a syndrome described as a state of exhaustion which may occur in a very wide range of occupational contexts [1] in which employees become cynical in relation to their work and experience decreased professional efficacy [2]. The most widely used definition of burnout is the one provided by Schaufeli et al. [2] and the $M a$ - slach Burnout Inventory - General Survey (MBI-GS) [3] has become the most commonly used measure in international research to assess burnout [4]. Another alternative in defining and measuring burnout is the measure proposed by Santinello [5] who describes burnout as a state of psychophysical exhaustion, deterioration of relations, and a sense of professional inefficacy and dis-

Funding: this work was supported by National Science Centre (project No. 2013/10/E/HS6/00163 entitled "Burnout from the neural perspective - exploring electrophysiological markers of burnout using dense array EEG," project manager: Krystyna Golonka).

Received: January 25, 2018. Accepted: July 11, 2018.

Corresponding author: Krystyna Golonka, Jagiellonian University, Institute of Applied Psychology, Łojasiewicza 4, 30-348 Kraków, Poland (e-mail: krystyna.golonka@uj.edu.pl). 
illusion. An instrument which is dedicated to assessing burnout in this approach is the Link Burnout Questionnaire (LBQ) [6]. The authors have decided to employ these 2 instruments to test the convergent validity of the Polish versions of MBI-GS and LBQ, in the same way as it was tested by Santinello [7] in the original Italian version of LBQ. Additionally, besides the popular MBI-GS, it is especially valuable to introduce LBQ as it is the only burnout measure introduced by the Psychological Test Laboratory of the Polish Psychological Association and has detailed psychometric characteristics and norms for several occupations [8].

It should be emphasized that burnout is linked to impairments in cognitive functioning [9] and impacts the mental and physical health of employees [10]. In consequence, burnout has a serious socio-economic impact in terms of decreased level of productivity, high resignation rate, and premature retirement $[4,11]$. Therefore, there is a need for empirical research that provides answers to questions related to the antecedents of burnout and further implications in intervention programs.

An extensive body of research shows a substantial list of antecedents of burnout and divides them into 2 separate groups of situational and individual factors [12]. Leiter and Maslach [13] have provided the Areas of Worklife model, which summarizes a wide range of research on workplace factors (areas) that contribute to burnout: workload, control, reward, community, fairness, and values. According to this model, chronic mismatches between people and their work settings lead to work-related stress and, as a consequence, to burnout. The authors of the Areas of Worklife model, which focuses on the degree of experienced congruence between the individual and the 6 dimensions of an individual's work environment, have extended the job-person paradigm to a broader conceptualization of employees in their job context. They propose that the greater the perceived misfit between an individual and a job, the greater the likelihood of burnout; converse- ly, the greater the consistency, the greater the likelihood of engagement with work.

The aforementioned areas of worklife have distinct relationships with the 3 burnout dimensions [14]. Moreover, longitudinal research has shown that different patterns of scores at a given time may predict organizational outcomes and burnout rates a year later [15]. Perceived incongruity between an individual and a job has implications for the dimensions of burnout syndrome $[4,16]$. The research conducted in the Polish population [17] showed that exhaustion was related to misfit between the areas of workload and control, which was consistent with the demand-control model of job stress [18]; cynicism was determined by mismatch in the area of fairness, which may be explained by the effort-reward imbalance model $[19,20]$. As of today, there is no study on the relationships between these 6 dimensions of an individual's job environment and the burnout dimensions proposed by Santinello [5]; therefore, it is interesting to expand this direction of research.

Personality plays a crucial role in the ways individuals react to the environment and empirical evidence suggests that certain aspects of personality may affect average stress levels [21] and stress-related disorders such as burnout [22]. Currently, most of the models of burnout try to explain its development through the interaction between personality and environment [23]. Among individual antecedents of burnout, which are repeatedly considered, there are personality traits such as a high level of neuroticism [24], negative affectivity [25], and anxiety [26]. The links between neuroticism, anxiety and burnout seem to be particularly interesting. Langelaan et al. [24] showed that high neuroticism was a core characteristic of burnout and was found to be a common predictor of all the dimensions of burnout [27]. The link between anxiety and burnout, particularly the dimension of emotional exhaustion, has also been empirically proven. Based on a review of research and an empirical study, Shirom and Ezrachi [28] 
showed that anxiety may function as a relatively stable trait in the burnout process.

There is also a growing body of research supporting the empirical overlap of emotional exhaustion and depression [10]. Iacovides et al. [23, p. 209] suggest that burnout and depression are "separate entities, although they may share several qualitative characteristics." The majority of these studies concluded that depression and burnout were 2 related but distinct constructs [29]. In a longitudinal study, Hakanen and Schaufeli [30] showed that burnout predicted depressive symptoms, but not vice versa. Ahola and Hakanen [31] proved that job strain predisposed to burnout, both directly and via depression. Van Dam [32] analyzed burnout symptoms in 2 separate subgroups (with mild and severe symptoms) and showed that depression was the strongest predictor of group membership. Some researchers emphasize the close interconnections between burnout and depression, indicating a wide range of similar symptoms [32,33]. Bianchi et al. [33] claim that there is no sufficient evidence to assume that burnout is a distinct entity and propose conceptualizing the 2 main burnout dimensions (exhaustion and depersonalization) as depressive responses to a stressful occupational environment. This relates to the important scientific debate over the extent to which burnout syndrome is a distinct illness with defined diagnostic criteria.

A deeper insight into possible links between burnout, anxiety and depression comes from psychophysiological research. For example, in a study in which error processing was analyzed, a pattern of anxiety-depression characteristics was observed [9]. Specifically, 2 components of event-related potential (ERP) in error-monitoring revealed similarity to ERPs that were observed in anxiety and depressive disorders. However, in emotional information processing, the results were not unequivocal: the ERP patterns in the burnout sample only to some extent resembled the electrophysiological changes that were observed in depression [34].
Therefore, based on the assumption that burnout should be explained as the transactional outcome of triggering work-related, contextual variables and certain individual characteristics, the authors have analyzed the relationships among 6 areas of worklife, personality traits (neuroticism, anxiety), and depression and burnout dimensions (according to definitions provided both by Schaufeli et al. [2] and Santinello [5]). The similarities and differences between the 2 conceptualizations of burnout are introduced. Additionally, in terms of the inconsistencies in the findings and conclusions whether burnout and depression are or are not distinct entities, the authors will focus on explaining the extent to which depression explains burnout syndrome.

\section{MATERIAL AND METHODS \\ Participants}

The study was conducted in the Institute of Applied Psychology at the Jagiellonian University, Kraków, Poland, on a non-clinical group of 100 participants $(\mathrm{N}=100 ; 40$ men), mean age 36.03 years $(\mathrm{SD}=8.06)$, all of which were employees with at least 1.5 years of work experience. The participants were recruited from an initial group of 272 volunteers who responded to an invitation to join a scientific project. Its aim and description was introduced via e-mails to organizations and business social networks. Volunteers were screened via the project website regarding general job (employee status, position, work experience, trade, relations at work with clients and/or co-workers) and personal characteristics (gender, age, education). Participants currently employed, active day-shift workers with direct contact with clients and/or co-workers were included in the sample. Additionally, questions on health problems were included to avoid potential confounders. The questions referred to neurological illness, serious head injuries, and addictions (closed "yes/no" question). Only participants who answered "no" were included in the final sample. Subjects with health problems and drug addiction were excluded from the study. 
To select a homogeneous group, the authors decided to recruit only subjects with higher education, but they were not restricted to any particular occupation. The final sample consisted of 100 participants varying in scores on burnout and job characteristics. Participants were divided into 2 subgroups based on the results of the Maslach Burnout Inventory - General Survey (MBI-GS) [3], and the Areas of Worklife Survey (AWS) [36,37]. The burnout group consisted of participants who had high scores (> 3) in 2 burnout dimensions: exhaustion and cynicism. As diminished efficacy is not so evident in a non-clinical burnout sample [9], efficacy was controlled but was not an inclusion criterion. Areas of Worklife Survey method was used for ensuring the job-related context of burnout symptoms. The inclusion criteria for the burnout group were low scores $(<3)$ in at least 3 of 6 AWS scales (Workload, Control, Reward, Community, Fairness, and Values), which indicated lower degree of perceived alignment between the workplace and the individual's preferences. Subjects with high scores on burnout were matched with the control group (without burnout symptoms) in terms of gender and age. During the tests all participants were interviewed according to a checklist regarding health problems, workload, family, additional duties, and drugs. The subjects did not report any serious health problems that could have influenced their psychological state (in the final sample only several participants with mild musculoskeletal ailments, tendency to hypertension, as well as taking supplements and herbal medications, were included). None were in psychiatric treatment at that time.

All participants in the selected group completed the second burnout measure (LBQ) and questionnaires on individual characteristics. The study protocol was approved by the Bioethics Commission at the Jagiellonian University and was carried out in accordance with the recommendations of the APA Ethics Code. Subjects were paid for their participation. Each participant gave written informed consent.

\section{Methods}

Burnout

Burnout was measured using the Polish version of the Maslach Burnout Inventory - General Scale (MBI-GS) [35] and the Link Burnout Questionnaire (LBQ) [6].

The MBI-GS measures 3 dimensions of burnout and consists of 16 items that are rated on a 7-point frequency scale (ranging from 0 - "never" to 6 - "every day"). The items measuring exhaustion (5 items) relate to both physical and emotional exhaustion. The cynicism dimension (5 items) reflects detachment and distance from work itself. Finally, professional efficacy (6 items) relates to both social and non-social aspects of occupational accomplishments and one's expectation of effectiveness at work.

Previous studies concerning the psychometric evaluation of the Polish version of MBI-GS have proven its satisfactory psychometric properties [35]. Cronbach's $\alpha$ coefficients based on the sample are $\alpha_{\text {exhaustion }}=0.922$, $\alpha_{\text {cynicism }}=0.9101$, and $\alpha_{\text {efficacy }}=0.889$.

The LBQ measures 4 dimensions of burnout and includes 24 items that are rated on a 6-point scale (ranging from 1 - "never" to 6 - "every day"):

- psychophysical exhaustion, which describes the subjective state of being exhausted (6 items);

- relationship deterioration, which characterizes the quality of relations with clients (6 items);

- sense of professional inefficacy, which is related to evaluation of an employee's own professional competences (6 items);

- disillusion, which relates to existential expectations (6 items).

Previous studies have revealed that - except for the subscale for the sense of professional inefficacy - the Polish version of LBQ has satisfactory internal validity and stability [8]. The results have varied depending on the specific occupation of the sample. The weakest reliability has been found for therapists. Cronbach's $\alpha$ coefficients based on 
this sample are $\alpha_{\text {psychophysical exhaustion }}=0.847, \alpha_{\text {relationship deteriora- }}$ tion $=0.6049, \alpha_{\text {sense of inefficacy }}=0.6922$, and $\alpha_{\text {disillusion }}=0.9031$.

\section{Work conditions}

Work conditions were assessed using the Polish version of the Areas of Worklife Scale (AWS) which comprised 29 items which created distinct scores for each of the 6 areas of worklife (workload, control, reward, community, fairness, and values) [36]. Workload refers to the relationship between work demands and time and resources. Control refers to the role of clarity within an organization, which thus provides a clear understanding of expectations and responsibilities. Reward refers to recognition from other people as well as the satisfaction that employees experience in the workplace. Community includes the quality of social relationships within the organization. Fairness in the workplace involves perception of organizational justice. Finally, values refer to the congruence between an employee's values, goals and expectations, and those of the organization. The items are framed as statements of perceived congruence or incongruence between an employee and a job.

The items measuring workload (6), control (3), reward (4), community (5), fairness (6), and values (5) are rated on a 5-point Likert scale ranging from 1 - "strongly disagree" to 5 - "strongly agree." The scale yielded a consistent factor structure across samples [37]. The Polish version of the AWS met psychometric standards. Cronbach's $\alpha$ coefficients were $\alpha_{\text {workload }}=0.848, \alpha_{\text {control }}=0.803, \alpha_{\text {reward }}=0.839$, $\alpha_{\text {community }}=0.894, \alpha_{\text {fairness }}=0.864$, and $\alpha_{\text {values }}=0.757$.

\section{Neuroticism}

Neuroticism was measured with the Polish version of the NEO Five-Factor Inventory (NEO-FFI) [38]. The NEOFFI is a 60 -item method that provides a brief comprehensive measure of the 5 domains of personality (neuroticism, extraversion, openness to experience, agreeableness, conscientiousness). Neuroticism measured by this method reflects anxiety, hostility, depression, self-consciousness, impulsiveness, and vulnerability. The reliability coefficient was $\alpha_{\text {neuroticism }}=0.89$.

\section{Depressive symptoms}

Depressive symptoms were measured with the Polish translation of Beck's Depression Inventory (BDI) [39-41]. This method assesses the severity of depressive symptoms. Participants rate 21 groups of statements and select the most appropriate for each group (e.g., for the group under the title sadness, people select either "I do not feel sad," "I feel sad much of the time," "I am sad all the time" or "I am so sad or unhappy that I cannot stand it"). The BDI demonstrates strong psychometric properties and reliably distinguishes between controls and depressed subjects. Cronbach's $\alpha$ coefficient was 0.897 .

\section{Trait anxiety}

Trait anxiety was measured using the trait version of the Polish adaptation of the State-Trait Anxiety Inventory (STAI) [42] which contained 2 subscales: the State Anxiety Scale (S-Anxiety) which evaluated the state of anxiety, and the Trait Anxiety Scale (T-Anxiety) which was used in this study and evaluated relatively stable aspects of "anxiety proneness," including general states of calmness, confidence, and security. There are 20 items allocated to T-Anxiety subscales. Responses assessed frequency of feelings "in general" ranging from 1 - "almost never" to 4 - "almost always." The reliability coefficient $\alpha$ was 0.911 .

Descriptive statistics of all variables and the correlation structure of the data are presented in Table 1 and Table 2, respectively.

\section{Statistics}

Two structural equation path models were created to quantify the relations between AWS and MBI-GS and LBQ, while controlling for STAI, NEO and BDI. Although path 
Table 1. Descriptive statistics of individual and organizational sample characteristics and t-tests between burnout and control subgroups in the study on burnout and its overlapping effects in employees

\begin{tabular}{|c|c|c|c|c|}
\hline \multirow[t]{2}{*}{ Variable } & \multicolumn{2}{|c|}{$\begin{array}{c}\text { Respondents } \\
(\mathrm{N}=100) \\
\mathrm{M} \pm \mathrm{SD}\end{array}$} & \multirow[t]{2}{*}{$\mathrm{t}(\mathrm{df})$} & \multirow[t]{2}{*}{$\mathrm{p}$} \\
\hline & $\begin{array}{l}\text { burnout } \\
(\mathrm{N}=50)\end{array}$ & $\begin{array}{l}\text { controls } \\
(\mathrm{N}=50)\end{array}$ & & \\
\hline$\overline{\text { Age }}$ & $37.22 \pm 7.62$ & $34.84 \pm 8.39$ & $-1.48(98)$ & n.s \\
\hline women & $38.47 \pm 7.30$ & $35.07 \pm 8.89$ & $-1.62(58)$ & n.s \\
\hline men & $35.35 \pm 7.90$ & $34.50 \pm 7.82$ & $-0.34(38)$ & n.s \\
\hline \multicolumn{5}{|l|}{ Areas of Worklife Survey (AWS) } \\
\hline workload & $2.28 \pm 0.79$ & $3.15 \pm 0.82$ & $5.45(98)$ & $* * *$ \\
\hline control & $2.61 \pm 0.99$ & $3.47 \pm 0.70$ & $5.02(98)$ & $* * *$ \\
\hline reward & $2.53 \pm 0.77$ & $3.42 \pm 0.65$ & $6.28(98)$ & $* * *$ \\
\hline community & $2.76 \pm 0.93$ & $3.60 \pm 0.75$ & $4.97(98)$ & $* * *$ \\
\hline fairness & $2.06 \pm 0.70$ & $3.09 \pm 0.60$ & $7.89(98)$ & $* * *$ \\
\hline values & $2.79 \pm 0.69$ & $3.63 \pm 0.58$ & $6.61(98)$ & $* * *$ \\
\hline \multicolumn{5}{|l|}{ Maslach Burnout Inventory (MBI) } \\
\hline exhaustion & $4.12 \pm 0.99$ & $1.93 \pm 0.74$ & $-12.56(98)$ & $* * *$ \\
\hline cynicism & $3.99 \pm 0.89$ & $1.46 \pm 0.66$ & $-16.07(98)$ & $* * *$ \\
\hline efficacy & $3.37 \pm 1.12$ & $4.59 \pm 0.62$ & $6.75(98)$ & $* * *$ \\
\hline \multicolumn{5}{|l|}{ Link Burnout Questionnaire (LBQ) } \\
\hline psychophysical exhaustion & $25.66 \pm 5.47$ & $16.08 \pm 4.47$ & $-9.59(98)$ & $* * *$ \\
\hline relationship deterioration & $21.02 \pm 4.95$ & $16.02 \pm 3.58$ & $-5.79(98)$ & $* * *$ \\
\hline sense of professional inefficacy & $16.90 \pm 4.82$ & $11.42 \pm 2.54$ & $-7.11(98)$ & $* * *$ \\
\hline disillusion & $25.50 \pm 5.75$ & $14.50 \pm 5.32$ & $-9.93(98)$ & $* * *$ \\
\hline \multicolumn{5}{|l|}{ NEO Five-Factor Inventory (NEO) } \\
\hline neuroticism & $26.82 \pm 7.74$ & $15.12 \pm 6.15$ & $-8.37(98)$ & $* * *$ \\
\hline \multicolumn{5}{|l|}{ State-Trait Anxiety Inventory (STAI) } \\
\hline anxiety & $49.80 \pm 8.69$ & $39.02 \pm 7.01$ & $-6.83(98)$ & $* * *$ \\
\hline \multicolumn{5}{|l|}{ Beck's Depression Inventory (BDI) } \\
\hline depression & $14.04 \pm 7.53$ & $4.76 \pm 4.68$ & $-7.40(98)$ & $* * *$ \\
\hline
\end{tabular}

n.s. - non significant $\mathrm{p}>0.05 ; * * * \mathrm{p}<0.001$.

models are sometimes referred to as causal models, in this study no causal relations are stated. The analysis was conducted in Mplus 7 software [43] with maximum likelihood estimation and delta parameterization. No missing data was observed.

\section{RESULTS}

Both path models were based on the same dataset and were focused on predicting burnout measures (LBQ and MBI-GS) using predictors on the left side of the models: AWS scale, neuroticism, anxiety and depression. 


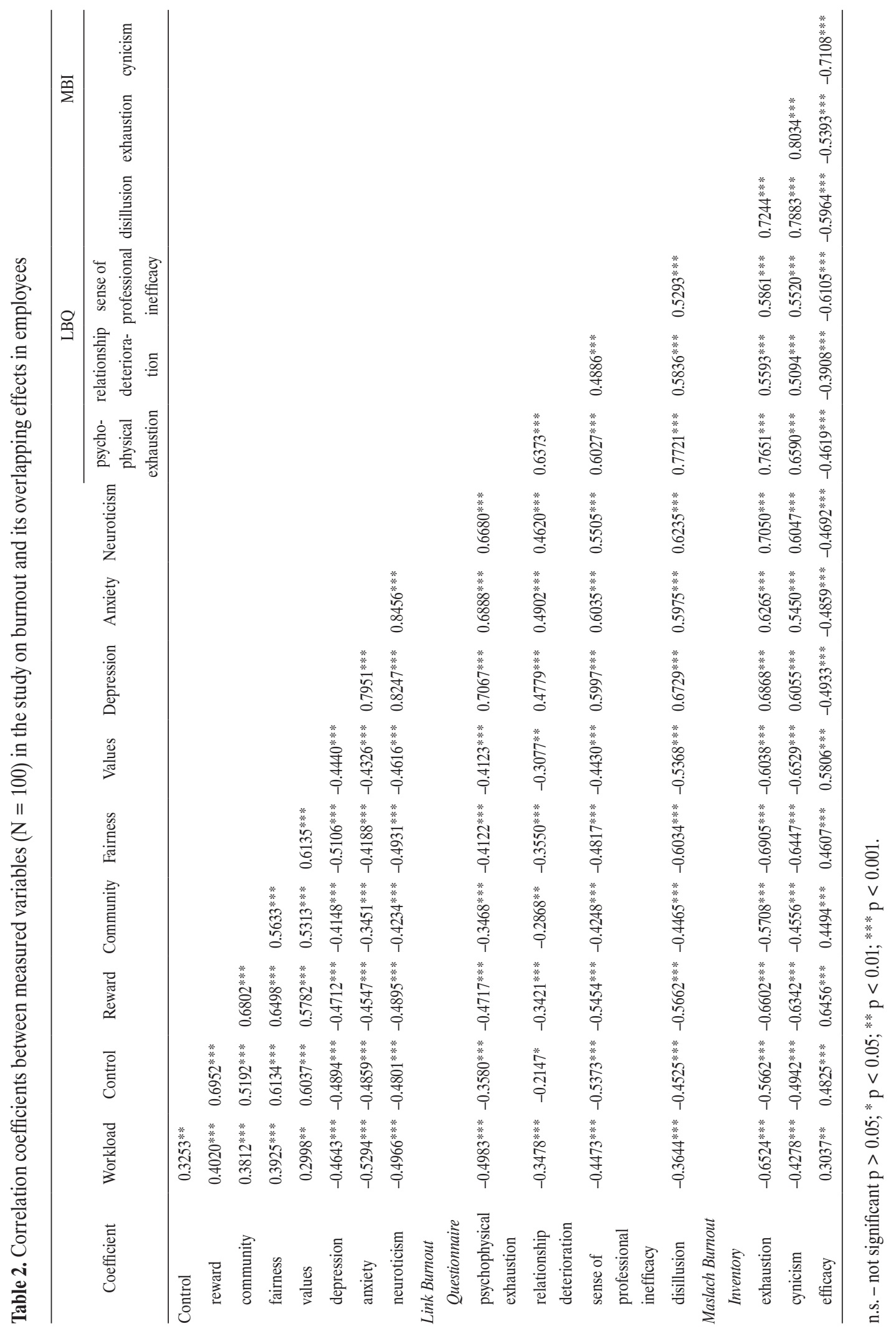




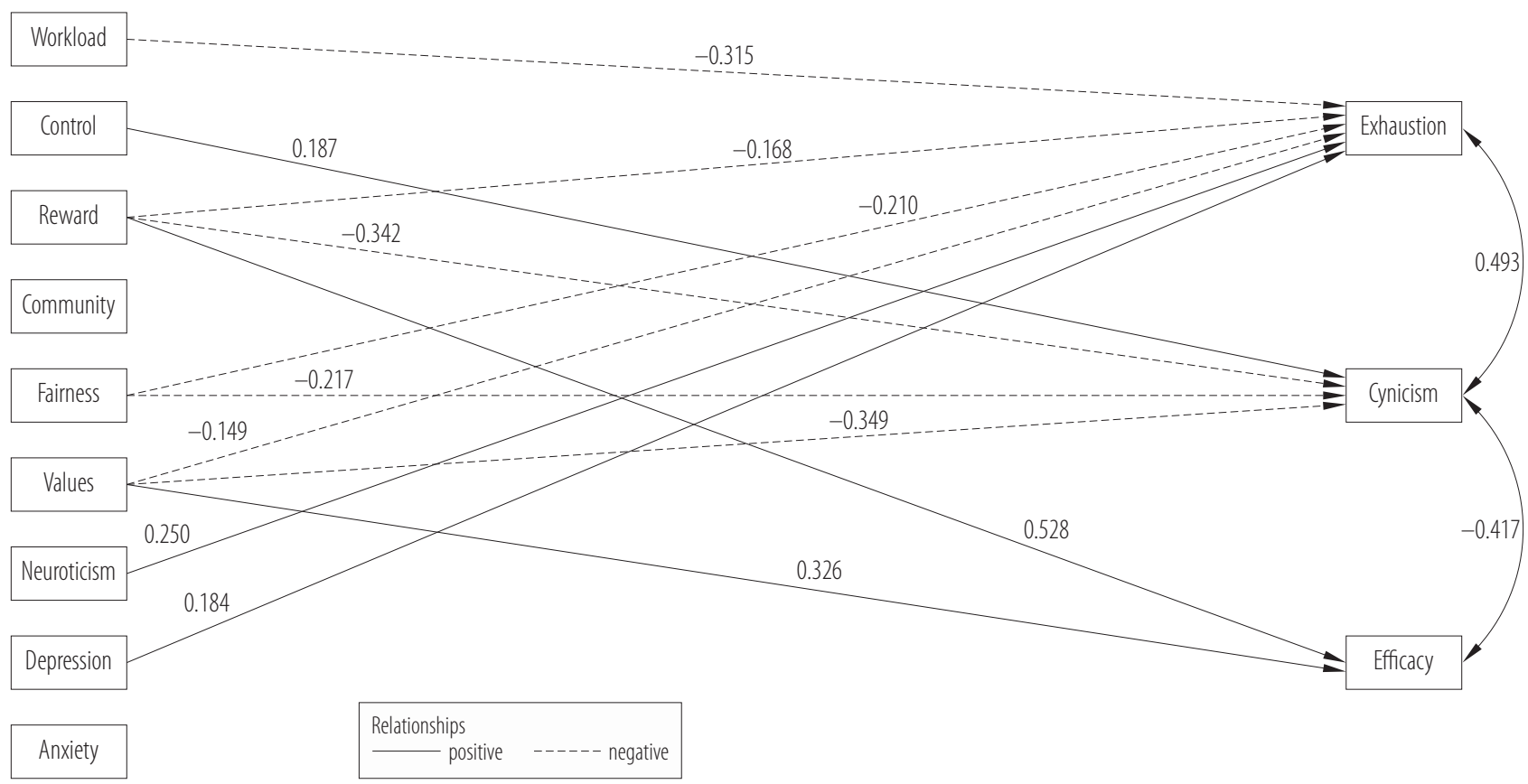

Non-significant paths and correlations between exogenous variables are omitted in the picture to achieve better transparency and may be found in Table 2 and Table 3.

Figure 1. The Maslach Burnout Inventory - General Survey (MBI-GS) prediction model with standardized estimates (N = 100)

The models were identified, thus the model fit could not be accessed (i.e., root mean square error of approximation $($ RMSEA $)=0.000, \mathrm{CFI}=1.000)$ and the models had to be compared based on the percentage of explained variance. The descriptive statistics of individual and organizational characteristics and comparisons between burnout subjects and controls are presented in Table 1. The correlation matrix of all studied variables is presented in Table 2.

Model 1 predicts MBI-GS (Figure 1 and Table 3) and shows that the exhaustion subscale is negatively related to work conditions such as workload ( $p<0.001)$, rewards $(p=0.04)$, fairness $(p=0.004)$, values $(p=0.028)$, as well as positively to neuroticism $(\mathrm{p}=0.016)$ and depression $(p=0.046)$. Based on the predictors, $77 \%$ of exhaustion variance was explained. Cynicism related positively to control $(p=0.041)$, and negatively - to rewards $(p=0.001)$, fairness $(p=0.016)$ and values $(p<0.001)$. The model explained $65 \%$ of cynicism variance. Efficacy may be predicted only based on rewards $(\mathrm{p}<0.001)$ and values ( $\mathrm{p}=0.001) ; 53 \%$ of its variance was explained by the model. Individual traits such as neuroticism and depression were predictive only for exhaustion, while anxiety was not related to any MBI-GS dimension.

While controlling for all predictors in the model, correlations between MBI-GS subscales are lower, and the relation between exhaustion and efficacy is non-significant.

Model 2 (Figure 2 and Table 4) was designed to predict LBQ burnout measure, based on the same predictors as Model 1. Psychophysical exhaustion was positively related to control $(p=0.048)$ and depression $(p=0.001)$, and negatively - to rewards $(p=0.025)$. The predictors explained $59 \%$ of psychophysical exhaustion. Relationship deterioration was predicted only by control $(p=0.031)$, and $31 \%$ of its variance was explained in the model. Sense of professional inefficacy was related only to anxiety $(p=0.048)$ but $50 \%$ of its variance was explained. Disillu- 
sion was negatively related to rewards $(p=0.026)$ and fairness $(p=0.01)$, and positively to depression $(p=0.003)$. Overall, $59 \%$ of disillusion variance was explained by the model. Controlling for predictors in the model caused correlations between the LBQ dimensions to be reduced, and the correlation between sense of professional inefficacy and disillusion became non-significant.

\section{DISCUSSION}

This study has provided evidence for the important role of both individual characteristics and organizational factors that contribute to burnout; however, different factors play crucial roles, depending on the conceptualization of burnout.

In Model 1, burnout has been measured with the use of MBI-GS. The results indicate that exhaustion is largely explained not only by the misfit in the areas of workload, values, reward, and fairness, but also by individual factors such as neuroticism and depression. The relationship between exhaustion and workload is consistent with previous theoretical models [18] and findings [14]. The links to fairness, values and rewards emphasize the broader context of exhaustion, indicating that its source might be in social and motivational factors.

The link between neuroticism and exhaustion has consistently been supported by previous research $[44,45]$, thus showing the role of this personality trait as a factor that may predispose an employee to stress-related consequences such as burnout. Additionally, in this study exhaustion shows an empirical overlap with depression which is consistent with a huge body of research $[23,46,47]$.

The next burnout dimensions in Model 1 (cynicism and efficacy) are also determined by their relationships with values and reward, which suggests their crucial role in determining burnout. A mismatch in values occurs when there is a discrepancy between personal and organizational aims and standards which may lead to serious conflict and, consequently, to exhaustion, cynicism and lack of effi-
Table 3. Standardized estimates for Maslach Burnout Inventory General Survey (MBI-GS) path model (N = 100) in the study on burnout and its overlapping effects in employees

\begin{tabular}{|c|c|c|c|}
\hline Path & $\begin{array}{l}\text { Standardized } \\
\text { estimate }\end{array}$ & SE & $\mathrm{p}$ \\
\hline \multicolumn{4}{|c|}{ Exhaustion $\left(\mathrm{R}^{2}=0.771\right)$} \\
\hline workload $\rightarrow$ & -0.315 & 0.060 & $<0.001$ \\
\hline control $\rightarrow$ & 0.033 & 0.074 & 0.656 \\
\hline reward $\rightarrow$ & -0.168 & 0.082 & 0.040 \\
\hline community $\rightarrow$ & -0.014 & 0.069 & 0.839 \\
\hline fairness $\rightarrow$ & -0.210 & 0.073 & 0.004 \\
\hline values $\rightarrow$ & -0.149 & 0.068 & 0.028 \\
\hline neuroticism $\rightarrow$ & 0.250 & 0.104 & 0.016 \\
\hline depression $\rightarrow$ & 0.184 & 0.092 & 0.046 \\
\hline anxiety $\rightarrow$ & -0.116 & 0.100 & 0.250 \\
\hline \multicolumn{4}{|l|}{ Cynicism $\left(\mathrm{R}^{2}=0.649\right)$} \\
\hline workload $\rightarrow$ & -0.068 & 0.073 & 0.356 \\
\hline control $\rightarrow$ & 0.187 & 0.092 & 0.041 \\
\hline reward $\rightarrow$ & -0.342 & 0.100 & 0.001 \\
\hline community $\rightarrow$ & 0.150 & 0.086 & 0.080 \\
\hline fairness $\rightarrow$ & -0.217 & 0.090 & 0.016 \\
\hline values $\rightarrow$ & -0.349 & 0.083 & $<0.001$ \\
\hline neuroticism $\rightarrow$ & 0.148 & 0.129 & 0.250 \\
\hline depression $\rightarrow$ & 0.207 & 0.114 & 0.070 \\
\hline anxiety $\rightarrow$ & -0.035 & 0.124 & 0.777 \\
\hline \multicolumn{4}{|l|}{ Efficacy $\left(\mathrm{R}^{2}=0.528\right)$} \\
\hline workload $\rightarrow$ & -0.045 & 0.085 & 0.597 \\
\hline control $\rightarrow$ & -0.116 & 0.106 & 0.272 \\
\hline reward $\rightarrow$ & 0.528 & 0.113 & $<0.001$ \\
\hline community $\rightarrow$ & -0.055 & 0.099 & 0.581 \\
\hline fairness $\rightarrow$ & -0.081 & 0.104 & 0.437 \\
\hline values $\rightarrow$ & 0.326 & 0.095 & 0.001 \\
\hline neuroticism $\rightarrow$ & 0.096 & 0.149 & 0.519 \\
\hline depression $\rightarrow$ & -0.182 & 0.132 & 0.166 \\
\hline anxiety $\rightarrow$ & -0.174 & 0.144 & 0.226 \\
\hline \multicolumn{4}{|l|}{ Exhaustion } \\
\hline$\leftrightarrow$ cynicism & 0.493 & 0.076 & $<0.001$ \\
\hline$\leftrightarrow$ efficacy & -0.030 & 0.100 & 0.768 \\
\hline Cynicism $\leftrightarrow$ efficacy & -0.417 & 0.083 & $<0.001$ \\
\hline
\end{tabular}

Correlations between exogenous variables were the same as in Table 2. 


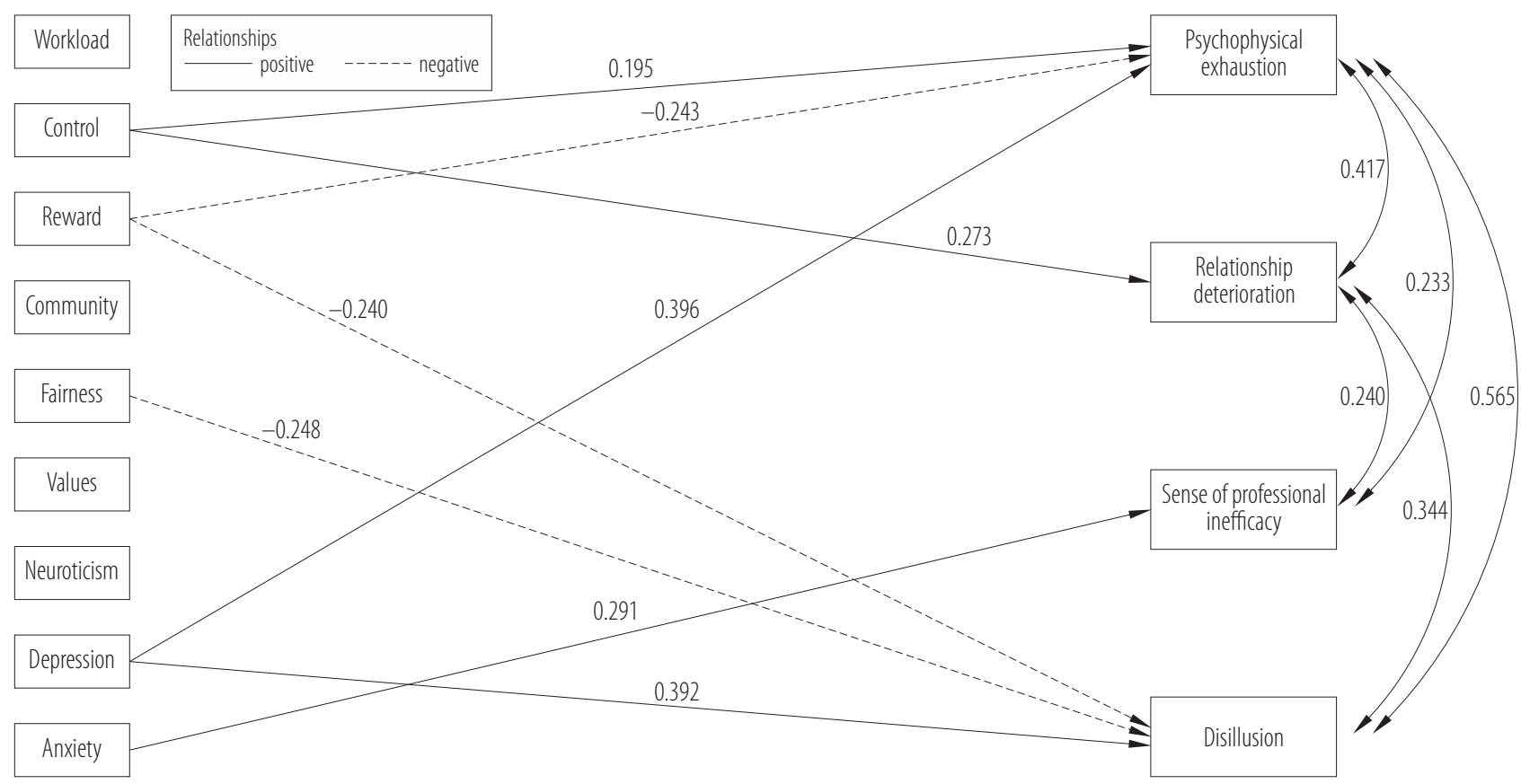

Non-significant paths and correlations between exogenous variables are omitted in the picture to achieve better transparency and may be found in Table 2 and Table 4.

Figure 2. The Link Burnout Questionnaire (LBQ) prediction model with standardized estimates ( $\mathrm{N}=100)$

Table 4. Standardized estimates for Link Burnout Questionnaire (LBQ) path model $(\mathrm{N}=100)$ in the study on burnout and its overlapping effects in employees

\begin{tabular}{|c|c|c|c|c|}
\hline & Path & $\begin{array}{l}\text { Standardized } \\
\text { estimate }\end{array}$ & SE & $\mathrm{p}$ \\
\hline \multicolumn{5}{|c|}{ Psychophysical exhaustion $\left(\mathrm{R}^{2}=0.594\right)$} \\
\hline workload $\rightarrow$ & & -0.140 & 0.079 & 0.075 \\
\hline control $\rightarrow$ & & 0.195 & 0.099 & 0.048 \\
\hline reward $\rightarrow$ & & -0.243 & 0.109 & 0.025 \\
\hline community $\rightarrow$ & & 0.076 & 0.092 & 0.408 \\
\hline fairness $\rightarrow$ & & 0.025 & 0.097 & 0.799 \\
\hline values $\rightarrow$ & & -0.105 & 0.090 & 0.242 \\
\hline neuroticism $\rightarrow$ & & 0.034 & 0.138 & 0.806 \\
\hline depression $\rightarrow$ & & 0.396 & 0.121 & 0.001 \\
\hline anxiety $\rightarrow$ & & 0.246 & 0.133 & 0.064 \\
\hline \multicolumn{5}{|c|}{ Relationship deterioration $\left(\mathrm{R}^{2}=0.594\right)$} \\
\hline workload $\rightarrow$ & & -0.061 & 0.102 & 0.552 \\
\hline control $\rightarrow$ & & 0.273 & 0.127 & 0.031 \\
\hline reward $\rightarrow$ & & -0.155 & 0.141 & 0.270 \\
\hline community $\rightarrow$ & & -0.015 & 0.120 & 0.901 \\
\hline
\end{tabular}


Table 4. Standardized estimates for Link Burnout Questionnaire (LBQ) path model $(\mathrm{N}=100)$ in the study on burnout and its overlapping effects in employees - cont.

\begin{tabular}{|c|c|c|c|}
\hline Path & $\begin{array}{l}\text { Standardized } \\
\text { estimate }\end{array}$ & SE & $\mathrm{p}$ \\
\hline \multicolumn{4}{|l|}{ Relationship deterioration $\left(\mathrm{R}^{2}=0.594\right)$ - cont. } \\
\hline fairness $\rightarrow$ & -0.139 & 0.126 & 0.270 \\
\hline values $\rightarrow$ & -0.072 & 0.117 & 0.536 \\
\hline neuroticism $\rightarrow$ & -0.032 & 0.180 & 0.860 \\
\hline depression $\rightarrow$ & 0.184 & 0.159 & 0.247 \\
\hline anxiety $\rightarrow$ & 0.307 & 0.172 & 0.074 \\
\hline \multicolumn{4}{|l|}{ Sense of professional inefficacy $\left(\mathrm{R}^{2}=0.315\right)$} \\
\hline workload $\rightarrow$ & -0.104 & 0.087 & 0.234 \\
\hline control $\rightarrow$ & -0.140 & 0.109 & 0.199 \\
\hline reward $\rightarrow$ & -0.179 & 0.120 & 0.135 \\
\hline community $\rightarrow$ & -0.014 & 0.102 & 0.893 \\
\hline fairness $\rightarrow$ & -0.038 & 0.108 & 0.721 \\
\hline values $\rightarrow$ & -0.022 & 0.100 & 0.824 \\
\hline neuroticism $\rightarrow$ & -0.143 & 0.153 & 0.350 \\
\hline depression $\rightarrow$ & 0.251 & 0.135 & 0.064 \\
\hline anxiety $\rightarrow$ & 0.291 & 0.147 & 0.048 \\
\hline \multicolumn{4}{|l|}{ Disillusion $\left(\mathrm{R}^{2}=0.500\right)$} \\
\hline workload $\rightarrow$ & 0.059 & 0.079 & 0.453 \\
\hline control $\rightarrow$ & 0.183 & 0.098 & 0.063 \\
\hline reward $\rightarrow$ & -0.240 & 0.108 & 0.026 \\
\hline community $\rightarrow$ & 0.032 & 0.092 & 0.725 \\
\hline fairness $\rightarrow$ & -0.248 & 0.096 & 0.010 \\
\hline values $\rightarrow$ & -0.159 & 0.090 & 0.076 \\
\hline neuroticism $\rightarrow$ & 0.028 & 0.138 & 0.838 \\
\hline depression $\rightarrow$ & 0.362 & 0.121 & 0.003 \\
\hline anxiety $\rightarrow$ & 0.135 & 0.133 & 0.311 \\
\hline \multicolumn{4}{|l|}{ Psychophysical exhaustion $\left(\mathrm{R}^{2}=0.594\right)$} \\
\hline$\leftrightarrow$ relationship deterioration & 0.416 & 0.083 & $<0.001$ \\
\hline$\leftrightarrow$ sense of professional inefficacy & 0.233 & 0.095 & 0.014 \\
\hline$\leftrightarrow$ disillusion & 0.565 & 0.068 & $<0.001$ \\
\hline \multicolumn{4}{|l|}{ Relationship deterioration } \\
\hline$\leftrightarrow$ sense of professional inefficacy & 0.240 & 0.094 & 0.011 \\
\hline$\leftrightarrow$ disillusion & 0.344 & 0.088 & $<0.001$ \\
\hline Sense of professional inefficacy $\leftrightarrow$ Disillusion & 0.073 & 0.099 & 0.466 \\
\hline
\end{tabular}

Correlations between exogenous variables were the same as in Table 2. 
cacy. Additionally, if rewards are properly distributed, this may result in significant stress and lead to various burnout symptoms. But interconnections are consistent with objective job stress models such as the effort-reward imbalance model [48].

In addition the misfit in values and rewards, the significant predictors of cynicism were fairness and control. Interestingly, our results show that the higher the extent of employee participation in organizational decisions, the higher the level of cynicism; this contradicts models of stress such as the job demands-resources model [49]. Such a result may suggest indirect effects of control on remaining areas of worklife and should be explored in further research. However, it should be emphasized that the correlation coefficients between control and burnout symptoms were negative; this indicates that - as is consistent with the literature - the higher the control, the lower the burnout scores. The analysis of path models of the specific structure of predictors and their interconnections should be taken into consideration. It should be noted that since the models are not based on an experimental design, they do not represent "effects while controlling for covariates" (i.e., held constant due to design), but rather "associations adjusted for covariates" (i.e., conditional on values of a specific set of covariates). This distinction is crucial in understanding the paradoxical reversal of coefficient signs often seen when including additional covariates in regression models [50,51]. This reversal is caused by explaining the variance of the dependent variable by 2 or more sources of variance which are also correlated, thus making the explained variance conditional on the size of correlation between the predictors, similarly to partial correlations.

This may be observed when simple bivariate correlations between AWS subscales (e.g., control, community or values) and burnout scales are compared to analogous relations in the models which account for associations with other variables. This means that the discrepancy between the acquired results and theoretical assumptions might be explained by the statistical procedure. Also, the p-values of those coefficients are relatively high (i.e., $p=0.048$ ), which means that the results need to be interpreted carefully so as not to overgeneralize.

It should be noted that the problem of sign reversal needs to be considered when interpreting all non-experimental or non-causal models because this is a common problem in all analyses in which confounding factors cannot be controlled by design.

In Model 2, which was based on the LBQ, psychophysical exhaustion is linked to depression and mismatch in the area of reward. These 2 factors are universal determinants of exhaustion in both analyzed burnout conceptualizations. As in Model 1, the authors also observed positive relations between control and burnout dimensions in Model 2, in this case with psychophysical exhaustion and deterioration of relations.

Sense of professional inefficacy turned out to be linked only to the anxiety trait. Finally, disillusion is linked with depression and perception of mismatch in the area of fairness and reward; this makes it similar to some extent to exhaustion from Model 1.

Therefore, the analyzed models show some similarities and differences. First, there is a relationship between depression, mismatch in the area of reward, fairness and burnout dimensions in the 2 analyzed models. Additionally, there is a strong relationship between control and cynicism and relationship deterioration: in both models the higher the level of perceived control, the higher the detachment tendency. Finally, the area of community has been unrelated to burnout in both models. These results may be related to the sample characteristics: all participants have had higher education and $36 \%$ of the sample had managerial positions. Collaboration with others and direct contact with co-workers and clients have been the main work characteristics. There has been significant difference between burnout and matched non-burnout groups in terms of subjective control, community and val- 
ues, which may suggest that the subjects have been sufficiently diverse in these aspects. But the sample may be characterized by a high level of responsibility, autonomy and teamwork, and is homogenous in relation to some objective job characteristics.

Cynicism (MBI) and relationship deterioration (LBQ) relate to detachment, depersonalization and lower quality in relations with others. Along with psychophysical exhaustion, this lower motivation to be involved in work and relations with others is a core burnout symptom which, according to Santinello [7], is the most relational and most original component of the burnout syndrome concept. Interestingly, in both tested models our results point only to organizational predictors as determinants of cynicism and relationship deterioration. That is, one of the core burnout symptoms is explained only by organizational context. In terms of dissimilarities, it is worth emphasizing that only exhaustion shows relationships with individual characteristics in Model 1, while other burnout subcomponents are related only to organizational variables. Model 2 is more prone to individual characteristics: 3 out of 4 dimensions have revealed links with anxiety and depression. This may suggest that by using MBI-GS the authors refer mainly to organizational context, while LBQ is more sensitive to individual characteristics. This may be an important differentiation that could help in deciding which measure will be more appropriate in a particular study, depending on its aim and focus.

The correlation analysis between studied measures confirmed convergent validity between MBI and LBQ. All results are consistent with the tendencies that were observed on the Italian sample (for the "mixed group" comparable to our sample, which was comprised of different occupations). The authors have observed higher correlation coefficients than in the original LBQ version [7]. The highest correlation coefficients have been for

- MBI-cynicism and LBQ-disillusion ( $\mathrm{r}=0.79$, $\mathrm{p}<0.001)$
- MBI-exhaustion and LBQ-psychophysical exhaustion $(\mathrm{r}=0.77, \mathrm{p}<0.001)$,

- MBI-efficacy and LBQ-sense of professional inefficacy $(\mathrm{r}=0.69, \mathrm{p}<0.001)$.

Additionally, Cronbach's $\alpha$ in the range of $0.85-0.92$ indicates satisfactory reliabilities of the studied constructs. The lowest Cronbach's coefficient is observed for relationship deterioration and sense of professional inefficacy (0.61 and 0.69, respectively) in LBQ.

\section{Limitations}

The analyses are based on a sample of 100 participants of a non-clinical group of employees. Additionally, the group was homogenous in terms of education, with similar work characteristics (mental work, work based on collaboration with others) and matched in age and sex between burnout and control subjects. If the sample had also consisted of subjects with more severe symptoms and had been more differentiated in terms of work characteristics and other sample features, the results would possibly have revealed some other tendencies. Thus, as the sample does not reflect the characteristics of the general population, the results cannot be generalized and the conclusions should be drawn with caution.

\section{CONCLUSIONS}

The aim of the presented study was to analyze the organizational and individual characteristics in relation to 2 burnout measures: Maslach Burnout Inventory - General Survey (MBI-GS) and Link Burnout Questionnaire (LBQ). The results have revealed that both measurements are significantly related to organizational and individual factors. However, MBI-GS is mainly defined by organizational variables, while LBQ is strongly related to individual characteristics. It may be concluded that the measurements reveal significant overlaps with depression and anxiety, which confirms that burnout is not restricted to job-related determinants. Furthermore, if the authors could define some burnout di- 
mensions that are strictly related to individual characteristics (like sense of professional inefficacy in LBQ, which is related only with anxiety), this would emphasize the significance of individual context in developing burnout syndrome. Among individual characteristics, depression is revealed to be the most important variable. However, on the basis of the correlation studies the authors cannot assume that depressive symptoms are effects or causes of burnout; the authors can only state that this is an important component of burnout syndrome. Depression may be the cause or effect of burnout syndrome. The significant interdependencies between burnout and depression may indicate that symptoms of one disorder may intensify the symptoms of the other. Regardless of what the cause and effect relationship is, the strong intercorrelations between depression and burnout should raise the awareness of researchers and practitioners to predict and counteract the potential severe negative consequences of burnout. On the other hand, the organizational context relates significantly to burnout and some burnout dimensions are related only to work characteristics. Cynicism (MBI-GS) and relationship deterioration (LBQ) are only examples of job-related burnout dimensions. Thus, it seems unquestionable that there is an overlapping effect between burnout syndrome, depression and anxiety, but this is still not a complete picture of burnout syndrome. The specific, most original component of burnout, i.e., cynicism/relationship deterioration, seems to be determined mainly by organizational context.

\section{ACKNOWLEDGMENTS}

The authors would like to thank Michael Timberlake for proofreading and Katarzyna Popiel for her valuable contributions to data acquisition.

\section{REFERENCES}

1. Maslach C. What have we learned about burnout and health? Psychol Health. 2001;16(5):607-11, https://doi.org/ 10.1080/08870440108405530.
2. Schaufeli WB, Leiter M, Maslach C, Jackson SE. Maslach Burnout Inventory - General Survey. Manual. Palo Alto: Consulting Psychologists Press; 1996.

3. Maslach C, Jackson SE, Leiter MP. The Maslach Burnout Inventory - General Survey Manual. 3rd ed. Palo Alto: Consulting Psychologist Press; 1996.

4. Maslach C, Leiter MP, Jackson SE. Making a significant difference with burnout interventions: Researcher and practitioner collaboration. J Organ Behav. 2012;33(2):296-300, https://doi.org/10.1002/job.784.

5. Santinello M. Link Burnout Questionnaire, Manual. Firenze: Organizzazioni Speciali; 2007.

6. Santinello M, Altonoe G. Link Burnout Questionnaire. Firenze: Giunti OS; 2007.

7. Santinello M. [Link Burnout Questionnaire]. Warsaw: Pracownia Testów Psychologicznych PTP; 2014. Polish.

8. Jaworowska A. [Massimo Santinello Link Burnout Questionnaire. Polish normalisation]. Warsaw: Pracownia Testów Psychologicznych PTP; 2014. Polish.

9. Golonka K, Mojsa-Kaja J, Gawlowska M, Popiel K. Cognitive impairments in occupational burnout - Error processing and its indices of reactive and proactive control. Front Psychol. 2017;8:676, https://doi.org/10.3389/fpsyg. 2017.00676.

10. Schaufeli WB, Enzmann D. The burnout companion to study and practice: A critical analysis. 1st ed. London: Taylor \& Francis; 1998.

11. Schaufeli WB, Maslach C, Marek T, editors. Professional burnout: Recent developments in theory and research. Oxon: Taylor \& Francis; 2017, https://doi.org/10.4324/9781 315227979.

12. Cordes CL, Dougherty TW. A review and an integration of research on job burnout. Acad Manage Rev. 1993;18(4):62156, https://doi.org/10.2307/258593.

13. Leiter MP, Maslach C. Areas of worklife: A structured approach to organizational predictors of job burnout. In: Perrewe PL, Ganster DC, editors. Research in occupational stress and well-being. Oxford: Elsevier; 2004. p. 91-134. 
14. Leiter MP, Shaughnessy K. The areas of worklife model of burnout: Test of mediation relationships. Ergonomia IJE\&HF. 2006;28(4):327-41.

15. Maslach C, Leiter MP. Early predictors of job burnout and engagement. J Appl Psychol. 2008;93(3):498-512, https:// doi.org/10.1037/0021-9010.93.3.498.

16. Leiter MP, Gascón S, Martínez-Jarreta B. Making sense of work life: A structural model of burnout. J Appl Soc Psychol. 2010;40(1):57-75, https://doi.org/10.1111/j.1559-1816. 2009.00563.x.

17. Mojsa-Kaja J, Golonka K, Marek T. Job burnout and engagement among teachers - Worklife areas and personality traits as predictors of relationships with work. Int J Occup Med Environ Health. 2015;28(1):102-19, https://doi. org/10.13075/ijomeh.1896.00238.

18. Karasek R, Theorell T. Stress, productivity, and the reconstruction of working life. New York: Basic Books, Inc.; 1990.

19. Siegrist J. Adverse health effects of high-effort/low-reward conditions. J Occup Health Psychol. 1996;1(1):27-41, https:// doi.org/10.1037/1076-8998.1.1.27.

20. Bakker AB, Killmer CH, Siegrist J, Schaufeli WB. Effortreward imbalance and burnout among nurses. J Adv Nurs. 2000;31(4):884-91, https://doi.org/10.1046/j.1365-2648.2000. 01361.x.

21. Van der Linden D, Beckers DGJ, Taris TW. Reinforcement sensitivity theory at work: Punishment sensitivity as a dispositional source of job-related stress. Eur J Pers. 2007;21(7):889-909, https://doi.org/10.1002/per.660.

22. Cano-García FJ, Padilla-Muñoz EM, Carrasco-Ortiz MÁ. Personality and contextual variables in teacher burnout. Pers Individ Dif. 2005;38(4):929-40, https://doi.org/10.1016/ j.paid.2004.06.018.

23. Iacovides A, Fountoulakis KN, Kaprinis S, Kaprinis G. The relationship between job stress, burnout and clinical depression. J Affect Disord. 2003;75(3):209-21, https://doi. org/10.1016/S0165-0327(02)00101-5.

24. Langelaan S, Bakker AB, van Doornen LJP, Schaufeli WB. Burnout and work engagement: Do individual differences make a difference? Pers Individ Dif. 2006;40(3):521-32, https://doi.org/10.1016/j.paid.2005.07.009.

25. Zellars KL, Hochwarter WA, Perrewé PL, Hoffman N, Ford EW. Experiencing job burnout: The roles of positive and negative traits and states. J Appl Soc Psychol. 2004;34(5): 887-911, https://doi.org/10.1111/j.1559-1816.2004.tb02576.x.

26. Turnipseed DL. Anxiety and burnout in the health care work environment. Psychol Rep. 1998;82(2):627-42, https:/ doi.org/10.2466/pr0.1998.82.2.627.

27. Kokkinos CM. Job stressors, personality and burnout in primary school teachers. Br J Educ Psychol. 2007;77(1):229-43, https://doi.org/10.1348/000709905X90344.

28. Shirom A, Ezrachi Y. On the discriminant validity of burnout, depression, and anxiety: A re-examination of the burnout measure. Anxiety Stress Coping. 2003;16(1):83-99, https://doi.org/10.1080/1061580021000057059.

29. Bakker AB, Schaufeli WB, Demerouti E, Janssen P, van der Hulst R, Brouwer J. Using equity theory to examine the difference between burnout and depression. Anxiety Stress Coping. 2000;13(3):247-68, https://doi.org/10.1080/ 10615800008549265.

30. Hakanen JJ, Schaufeli WB. Do burnout and work engagement predict depressive symptoms and life satisfaction? A three-wave seven-year prospective study. J Affect Disord. 2002;141(2):415-24, https://doi.org/10.1016/ j.jad.2012.02.043.

31. Ahola K, Hakanen J. Job strain, burnout, and depressive symptoms: A prospective study among dentists. J Affect Disord. 2007;104(1):103-10, https://doi.org/10.1016/j.jad.20 07.03.004.

32. Van Dam A. Subgroup analysis in burnout: Relations between fatigue, anxiety, and depression. Front Psychol. 2016;7:90, https://doi.org/10.3389/fpsyg.2016.00090.

33. Bianchi R, Schonfeld IS, Laurent E. Burnout-depression overlap: A review. Clin Psychol Rev. 2015;36:28-41, https:// doi.org/10.1016/j.cpr.2015.01.004.

34. Golonka K, Mojsa-Kaja J, Popiel K, Marek T, Gawlowska M. Neurophysiological markers of emotion processing in 
burnout syndrome. Front Psychol. 2017;8:2155, https://doi. org/10.3389/fpsyg.2017.02155.

35. Mojsa J, Dylag A, Palczynska E. Psychometric properties of a Polish version of the Maslach Burnout Inventory-General Survey (MBI-GS) in a group of Information and Communication Technology (ICT) Specialists. Ergonomia IJE\&HF. 2006;28(4):351-61.

36. Leiter MP, Maslach C. Areas of worklife survey. California: Mind Garden, Inc.; 2000, 2001.

37. Leiter MP, Maslach C. The areas of worklife survey. Measure description. Wolfville: Acadia University, Center for Organizational Research and Development; 2004.

38. Zawadzki B, Strelau J, Szczepaniak P, Sliwińska M. [NEOFive Factor Inventory, Costa and McCrae]. Warsaw: Pracownia Testów Psychologicznych PTP; 1998. Polish.

39. Beck AT, Ward CH, Mendelson M, Mock J, Erbaugh J. An inventory for measuring depression. Arch Gen Psychiatry. 1961;4: 561-71, https://doi.org/10.1001/archpsyc.1961.01710120031004.

40. Beck AT, Steer RA, Garbin MG. Psychometric properties of the Beck Depression Inventory: Twenty-five years of evaluation. Clin Psychol Rev. 1988;88:77-100, https:/doi. org/10.1016/0272-7358(88)90050-5.

41. Parnowski T, Jernajczyk W. [Beck Depression Inventory in the assessment of healthy people and patients with affective disorders (pilot study)]. Psychiatr Pol. 1977;11:417-25. Polish.

42. Wrześniewski K, Sosnowski T. [State-Trait Anxiety Inventory. Polish adaptation of STAI]. Warsaw: Pracownia Testów Psychologicznych PTP; 1996. Polish.

43. Muthén LK, Muthén BO. Mplus statistical modeling software: Release 7.0. Los Angeles: Muthén \& Muthén; 2012.

44. Bakker AB, Van Der Zee KI, Lewig KA, Dollard MF. The relationship between the Big Five personality factors and burnout: A study among volunteer counselors. J Soc Psychol. 2006;146(1):31-50, https://doi.org/10.3200/ SOCP.146.1.31-50.

45. Kim HJ, Shin KH, Swanger N. Burnout and engagement: A comparative analysis using the Big Five personality dimensions. Int J Hosp Manag. 2009;28(1):96-104, https://doi. org/10.1016/j.ijhm.2008.06.001.

46. Ahola K, Honkonen T, Isometsä E, Kalimo R, Nykyri E, Aromaa A, et al. The relationship between job-related burnout and depressive disorders - Results from the Finnish Health 2000 Study. J Affect Disord.2005;88(1):55-62, https://doi.org/10.1016/j.jad.2005.06.004.

47. Bianchi R, Brisson R. Burnout and depression: Causal attributions and construct overlap. J Health Psychol. 2017;1:1359105317740415, https://doi.org/10.1177/13591053 17740415.

48. Siegrist J. Adverse health effects of high-effort/low-reward conditions. J Occup Health Psychol. 1996;1(1):27-41, https:// doi.org/10.1037/1076-8998.1.1.27.

49. Bakker AB, Demerouti E, Sanz-Vergel AI. Burnout and work engagement: The JD-R approach. Ann Rev Organ Psychol Organ Behav. 2014;1(1):389-411, https://doi. org/10.1146/annurev-orgpsych-031413-091235.

50. Arah OA. The role of causal reasoning in understanding Simpson's paradox, Lord's paradox, and the suppression effect: Covariate selection in the analysis of observational studies. Emerg Themes Epidemiol. 2008;5(1):5, https://doi. org/10.1186/1742-7622-5-5.

51. Tu YK, Gunnell D, Gilthorpe MS. Simpson's paradox, Lord's paradox, and suppression effects are the same phenomenon - The reversal paradox. Emerg Themes Epidemiol. 2008;5(1):2, https://doi.org/10.1186/1742-7622-5-2.

This work is available in Open Access model and licensed under a Creative Commons Attribution-NonCommercial 3.0 Poland License - http://creativecommons.org/ licenses/by-nc/3.0/pl/deed.en. 